\title{
Ecological Construction of Blended Teaching Model
}

\author{
Jinlu $\mathrm{Li}^{1}$, Yidong Sun ${ }^{2}$ \\ ${ }^{1}$ School of Education, Linyi University, China \\ ${ }^{2}$ Linyi University Feixian Campus, Shandong Province, China
}

Keywords: blended teaching model, classroom teaching, Ecology.

\begin{abstract}
Although the concept of ecological class has been universal, practice of ecological class in reality is not satisfying. The paper attempts to analyze class ecology that is based on blended teaching model of face-to-face teaching and e-learning. The paper hopes that it can appeal to every educator's thought and attention by building class ecology of blended teaching model.
\end{abstract}

\section{Raise of the question}

The ecological theory has been introduced to educational field and concepts such as ecological education, green class, ecological care and ecological class have come to our sight gradually, which means that traditional class has been viewed from the aspect of ecological education. In addition, with rapid development of technology and network techniques, artificial intelligence has been widely used in different fields, which also affects present education and teaching. The development of online education and distance education has been accepted. On January 20, 2018, "With the coming of artificial intelligence, is education still warm?" was released on column Focus of China Comment. "Network resources have been the common knowledge source for teachers and students", the awkwardness of education was reported in the article. Online teaching platforms such as Zhihuishu and Erya have been introduced by many universities and free MOOCs of more than four hundred subjects have been provided by Ministry of Education recently. We have to think about it and review traditional classroom teaching again. The blended teaching model in MOOCs has been accepted gradually. And it plays an intrinsic role with advantages on online and offline integration. The article is to discuss the construction of blended teaching model on the basis of ecological theory.

\section{Ecological deficiency of classroom teaching}

The construction of effective blended classroom is based on ecological theory. And ecological deficiency of classroom teaching still exists in specific classroom teaching.

\subsection{Ecological deficiency of classroom teaching objective}

Teaching objective is the result that the educator hopes the educatee to achieve. It embodies spirit of the age and represents the view of life and value of the educatee. However, ecological deficiency of some teaching objectives still exists in present classroom teaching, which makes teaching objectives not meet study requirements of the educatee. It is embodied in the following aspects. First, the knowledge-based examination system dominates value orientation of present classroom teaching. With knowledge objective stressed and emotion and motor skill objectives neglected in the objectives of classroom teaching, many students are of high scores and low abilities. On the other hand, because of the traditions formed in teaching in a long term, the development of teachers has been constricted in the stage of Concerning Situation and the teaching objective has been targeted to establish many containers imparting knowledge. In this case, the demand for self-development of students has been neglected and students become volume-produced products.

\subsection{Ecological deficiency of classroom teaching subject}

Under the leadership of wrong objectives of classroom teaching, ecological deficiency also exists 
among teachers and students, respectively the educator and the educatee. In recent years, teaching reforms have been promoted by curriculum reform of basic education and the student-centered concept has been rooted among the people. But teacher-centered concept has been followed in present classroom teaching. Teachers, the educator, dominate activity process, content arrangement and ultimate teaching evaluation of classroom teaching. Students, the educatee, can only accept vapid and boring knowledge passively as the audience. As for this kind of classroom teaching, the subject position of students is not embodied and required ecological balance is broken, which seriously affect the ecological development of classroom teaching.

\subsection{Ecological deficiency of classroom teaching environment}

It was found by ecologist Allee (Warder Clyde Allee, 1885-1955) that cluster could improve the survival ability of animal and he proposed Allee Law in ecology, explaining that over sparse or overstocked population was disadvantageous. With the law used in classroom environment, it is required to arrange class size scientifically to make students study and grow in healthy and harmonious ecological environment. According to the national conditions, it is proposed to arrange 40 50 students in a classroom in China. However, most classrooms contain 70 80 students and some classrooms even contain more than 90 students. The overstocked classroom environment seriously affects normal healthy mental and physical development of students. What's more, the ecological niche of seat arrangement will not be considered.

\subsection{Ecological deficiency of classroom teaching evaluation}

Because of the exam-oriented education for a long time, many exam-oriented concepts have been deeply rooted in the mind of many educators, which confines most teachers in the stage of Concerning Situation. These teachers pay more attention to utilize the 45 minutes of the class and improve scores of students. They do not concern the development of students. As for specific classroom teaching evaluation, the evaluation method, evaluation subject and evaluation content are all respectively single with teaching evaluation of utilitarianism. It is manifested that the participation of students in teaching evaluation is fairly insufficient. In most cases, students can only accept the evaluation of teachers, subject of the teaching evaluation. Therefore, knowledge determinism and study determinism are further reinforced. With biased classroom teaching evaluation mechanism, ecological deficiency of classroom teaching evaluation is serious.

\section{Ecological features of blended teaching model}

Blended teaching model mainly refers to organic integration of face-to-face classroom study and online study at present. Blended teaching model has been developed on the basis of blended study. And it is a new model highlighting online study and ensuring face-to-face study. With perfect integration of class and extracurricular study, online and offline study, the student-centered concept has been highlighted. According to the theory of educational ecology based on ecological balance and ecological system, classroom ecology, as an ecological system, has been formed under interrelation and interaction of four factors of teacher, student, environment and teaching information. The ecological features of blended teaching are mainly embodied in the following.

\subsection{Teaching objective of Concerning Students}

According to the research of Fuller and Brown, the professional development of teachers consists of several stages of concerning survival, concerning situation and concerning student. These stages also reflect development of the educator in teaching concept and teaching objective. The teaching objective of blended teaching mostly concerns development of students. With the change from knowledge orientation to ability orientation, it is expected that education can promote growth and overall development of students and enable them to apply knowledge and ability in life. In blended teaching model, teachers can fully respect students and treat all students equally. They also encourage students to doubt knowledge and have discussion. With their ability in investigation, independent innovation and problem solving motivated, the development of students has been really promoted. 


\subsection{Regression of classroom ecology subject}

As a specific ecological field, classroom teaching has its unique ecology subject. For a long time, the balance point for symbiosis of ecology subjects in classroom teaching has not been found. With integration of class and extracurricular study, online and offline study in blended teaching model, the symbiosis has been fully maintained.

In blended teaching, the value of teachers' teaching activities is realized by promoting development and growth of students. During the development process of students, the subjectivity and initiative of students have been fully embodied. With process and method of study executed by MOOCs platform and classroom discussion under the leadership of teachers, the student-centered concept can be embodied. Teachers play the role of leader to promote growth and development of students with development and growth of themselves at the same time. In actual interaction between teachers and students, teaching benefits teachers as well as students and they construct a specific ecological field together.

\subsection{Regression of classroom ecological environment}

Blended teaching integrates blended teaching and collaborative study. In collaborative study, the team member cannot exceed 7 and the class size is controlled about 40 , which is more beneficial to execution of blended teaching, communication between teachers and students, students and students and online and offline integration. As for online study, students are required to watch course video actively according to the task and chapter arranged by teachers. They shall also study and complete network video homework in the supervision of MOOCs platform. In addition, they shall participate in online exchange and discussion and relevant examination and test. As for offline study, students can understand corresponding content with interaction between teachers and students, collaboration among students. After class, they shall complete transfer of the knowledge they have studied. In the dynamic ecological field of blended teaching, teachers and students coexist in harmony with flexible and diverse seat arrangement. It is more beneficial to the development of students.

\subsection{Ecology of classroom teaching evaluation}

In blended teaching, the classroom teaching evaluation does not focus on a score but how to integrate two evaluation methods better. On the one hand, comprehensive evaluation is made by formative test for face-to-face class, participation in online discussion and homework completion of open classroom of students. On the other hand, study record cards are used to record time and study results of class study and online study of students, which can provide important reference data for teaching evaluation. Classroom teaching evaluation focuses on the process and dynamism of the evaluation, which means that it can provide an objective teaching evaluation with comprehensive evaluation of ultimate results and process. Diversified classroom teaching evaluation is embodied to maintain the ecological field of teaching evaluation.

\section{Ecological construction of blended teaching model}

Blended teaching model is a dynamic model in specific background. The kind of teaching model contains process such as generation, interaction, dialogue, collaboration, experience, investigation and creation. It is also a process for growth and development of teachers and students. Therefore, we try to construct blended teaching model from the perspective of ecological education and in combination with successful cases in domestic and foreign blended teaching. According to domestic and foreign researches, the optimized teaching result can be achieved only with organic integration of face-to-face classroom teaching and online teaching. The blended teaching model based on ecological horizon is a new teaching strategy. The design ideas of blended teaching model based on ecological horizon are as follows.

\subsection{Enrich online platforms to promote independent study}

Before class, teachers shall prepare relevant teaching resources according to teaching objective, teaching program and practical situation to complete MOOCs preparation, course design, question 
bank and uploading of related links. The teaching task, homework, online exchange and evaluation standard of next class shall be released on the network platform in advance. Student receive tasks on the network platform and complete study and discussion of related teaching contents with questions through teaching resources of MOOCs platform and micro-video. To complete the pre-class task issued by teachers, students have to watch MOOCs video and other online materials carefully. Teachers guide students by online solution. They can check feedback of students and judge preview, common questions and relevant knowledge background of students. With the interaction between teachers and teaching resources, students and resources, students and teachers before class, the ecological field of teaching and study has been maintained before class. On the one hand, it motivates enthusiasm of students for study. On the other hand, it improves ability of students in independent study.

\subsection{Execute classroom teaching to answer questions}

In classroom teaching, to highlight the ecology, classroom teaching may be divided into two parts of teachers' explanation and discussion between teachers and students. First, teachers have known about the understanding and mastery of students for knowledge by pre-class online exchange and understanding, so they shall mainly solve mind mapping, key and difficult points in combination with different resources to complete summarization of knowledge points, guide students to assimilate knowledge and bring the knowledge into existing knowledge system. Second, contents of the class shall be summarized to explain common questions, focus on solution of fallible problems and improve their knowledge. As for discussion between teachers and students, the problems to be discussed shall be extracted in combination with online feedback. With different groups, discuss can be made between students and students, teachers and students. Teachers shall guide students to master difficult points in discussion.

\subsection{Provide online platform to expand related knowledge}

Extracurricular period is the supplement of class and it can be used to help students comprehend and understand what they have learned. By releasing some tasks, referential platforms and reference materials, teachers can expand the knowledge of students and help students complete thinking questions and homework in high quality. Thus the initiative, enthusiasm and creativity of every student can be aroused to further maintain class and extracurricular ecological balance.

\subsection{Set multiple evaluation to motivate enthusiasm of students}

Blended teaching model supports multiple teaching evaluation. The teaching evaluation on teachers shall be considered from teaching design, teaching execution and teaching content. Specifically, it is evaluated from self-evaluation of teachers and evaluation of students. The study evaluation on students shall emphasize developmental evaluation and process evaluation and weaken summative evaluation, which is beneficial to motivate enthusiasm of students for study. For example, online evaluation can be made from the time for watching materials issued by teachers, online exchange with teachers, completion of online homework and visits to the online platform for comprehensive evaluation of $40 \%$. Class evaluation shall be made from attendance, participation in class discussion, collaborative study of groups and mastery of knowledge and it takes up 30\%. The completion of homework shall be evaluated independently and it takes up 10\%. Final grades take up $20 \%$. The evaluation system can arouse motivation of students for study and it is beneficial for teachers to know about conditions of students for better teaching.

\section{Discussion \& Conclusion}

The teaching environment in the new era provides better soil for the exploration of blended teaching model. But to construct optimized blended teaching model, especially to maintain ecological balance of the class in teaching process, it still requires further discussion in the network age of big data to promote mature blended teaching model. 


\section{References}

[1] Guan Yuefei: On Ecological Classroom and Its Construction [D]. Hefei, Anhui Normal University, 2007

[2] Zhu Guiqin, Zhai Xiuling: On Value Orientation of Ecological Classroom in Classroom Ecology Horizon [J]. Ecological Classroom, 2014 (4):109-111

[3] Xiao Xiaojing, etc.: Practice on Building Blended Teaching Model Based on Edmodo Platform [J]. Primary and Middle School Educational Technology, 2015 (13): 38-40

[4] Wei Shoulian, etc.: Construction and Application of Blended Teaching Model [J]. Journal of Zhaoqing University, 2014, 35 (2): 56-59

[5] Zhao Wei, etc.: Application of Blended Teaching Model Based on Micro-Class in Teaching Embryology Introduction [J]. Chinese Journal of Histochemistry and Cytochemistry, 2017 (3): 284-286 